\title{
Encapsulation of Anthocyanins from Black Rice (Oryza Sativa L.) Bran Extract using Chitosan-Alginate Nanoparticles
}

\author{
Rodel M. Bulatao ${ }^{1}$, John Paulo A. Samin ${ }^{1}$, Joel R. Salazar ${ }^{2} \&$ Juvy J. Monserate $^{2}$ \\ ${ }^{1}$ Rice Chemistry and Food Science Division, Philippine Rice Research Institute, Maligaya, Science City of \\ Muñoz, Nueva Ecija 3119, Philippines \\ ${ }^{2}$ Department of Chemistry, College of Arts and Sciences, Central Luzon State University, Science City of Muñoz, \\ Nueva Ecija 3119, Philippines \\ Correspondence: Rodel M. Bulatao, Rice Chemistry and Food Science Division, Philippine Rice Research \\ Institute, Maligaya, Science City of Muñoz, Nueva Ecija 3119, Philippines. E-mail: rudy_macky@yahoo.com \\ and rm.bulatao@philrice.gov.ph
}

Received: October 20, 2016

Accepted: February 3, $2017 \quad$ Online Published: April 11, 2017

doi:10.5539/jfr.v6n3p40

URL: https://doi.org/10.5539/jfr.v6n3p40

\begin{abstract}
This study was conducted to extract and encapsulate anthocyanins from black rice bran using chitosan-alginate nanoparticles. Ten black rice varieties were screened for the anthocyanin content and the variety with the highest anthocyanins was used for the encapsulation. The anthocyanins were extracted by defatting the bran with n-hexane and soaking it with $85 \%$ acidified ethanol. The crude anthocyanin extract (CAE) was freeze-dried at $-110^{\circ} \mathrm{C}$ for $48 \mathrm{~h}$ and then encapsulated in chitosan-alginate nanoparticles using two processes: ionic pre-gelation and polyelectrolyte complex formation. The mass ratio of chitosan and alginate polymers used in this study was 100:10. The treatments applied were as follows: $\mathrm{T}_{0^{-}}-0 \mathrm{mg}$ CAE, $\mathrm{T}_{1}-10 \mathrm{mg}$ CAE, $\mathrm{T}_{2}-20 \mathrm{mg}$ CAE, and $\mathrm{T}_{3}-30 \mathrm{mg}$ CAE. The resulting capsules were characterized in terms of chemical properties, surface morphology, particle size, polydispersive index, encapsulation efficiency, and 2, 2-diphenyl-1-picrylhydrazyl radical scavenging activity. Screening of rice samples indicated that Ominio bran had the highest anthocyanin content $(36.11 \mathrm{mg} / \mathrm{g})$. Anthocyanins were successfully encapsulated in the matrix as shown by the Scanning Electron Microscopy images and Fourier Transform Infrared spectra of the anthocyanin-loaded chitosan-alginate nanoparticles. Among the different concentrations of CAE, $\mathrm{T}_{3}$ had the highest encapsulation efficiency $(68.9 \%)$ and antioxidant scavenging activity (38.3\%) while $\mathrm{T}_{1}$ and $\mathrm{T}_{2}$ had the lowest. Ascending particle size was observed for $\mathrm{T}_{0}(358.5$ $\mathrm{nm}), \mathrm{T}_{3}(467.9 \mathrm{~nm}), \mathrm{T}_{1}(572.3 \mathrm{~nm})$, and $\mathrm{T}_{2}(635.9 \mathrm{~nm})$. All anthocyanin-loaded capsules were found to be of nano-size $(<1000 \mathrm{~nm})$. The study concluded that chitosan-alginate nanoparticles can be a good encapsulating material for anthocyanin.
\end{abstract}

Keywords: antioxidant, anthocyanins, black rice bran, chitosan-alginate nanoparticles, encapsulation, nanocapsule

\section{Introduction}

The Philippines being one of the top rice producers in the world produced about 18.15 million metric tons of paddy rice in 2015 (Philippine Statistics Authority, 2016). This huge amount of paddy rice contributed significantly in the generation of agricultural by-products such as rice bran. The bran is mainly used in the country as feed supplement for livestock production; however, several studies have been reported that it is a good source of protein, vitamins, micronutrients, and antioxidants (Moongngarm et al., 2012). The major antioxidants found in the bran particularly in pigmented rice are the anthocyanins.

Anthocyanins are one of the most abundant groups of flavonoids in nature and are responsible for the bright and colorful pigmentation of fruits, vegetables, and some cereal grains (Shipp \& Abdel-Aal, 2010). Anthocyanins are known to exhibit antimicrobial, anticancer, and anti-hyperglycemic properties (Andersen \& Jordheim, 2006). These compounds are very promising particularly as ingredient for functional and pharmaceutical products, but they have limited use due to their low stability under varying environmental conditions ( $\mathrm{pH}$, light, oxygen, and heat) and high reactivity with other compounds in the food matrix (Cavalcanti et al., 2011; Robert \& Fredes, 2015). 
Encapsulation technology is a process of entrapping bioactive compounds using a coating material, which protects them from degradation and provides efficient release and delivery for food and pharmaceutical applications (Nedovic et al., 2011). The coating materials, which form nanometer-size particles, can enhance cell permeability and stability of the compounds in the bloodstream (Yadav et al., 2012). The commonly used coating materials for encapsulation are natural polymers from plant, marine, microbial, and animal origins. This is due to their low or non-toxic property that makes them safe for food application (Wandrey et al., 2010). Chitosan and alginate are natural polymers that are non-toxic, biocompatible, and biodegradable (Skaugrud et al., 1999). Chitosan is obtained from deacetylation of chitin, a compound rich in the exoskeleton of arthropods, beaks of cephalopods (e.g. octopuses, squid, and cuttlefish), and cell walls and membranes of various microbes including fungi (Sharp, 2013). Chitosan is primarily composed of glucosamine and $\mathrm{N}$-acetyl glucosamine residues with $1,4-\beta$-linkage (Rinaudo, 2006). On the other hand, alginate is an anionic water-soluble polysaccharide extracted commercially from species of brown seaweed (Rowe et al., 2009). It is composed of $\alpha$-L-guluronic acid and $\beta$-D-mannuronic acid residues alternating in 1-4 linkage. When combined in a solution, these natural polymers can form a polyelectrolyte complex due to the interaction of the positively charged amine group of chitosan and the negatively charged carboxyl group of alginate. They can also form nanosize particles; thereby, increasing their chemical integrity in a wide range of $\mathrm{pH}$ (George \& Abraham, 2006; Gupta \& Karar, 2011).

To improve the stability and bioavailability of anthocyanins, microencapsulation technology has been applied in blackberry by thermal gelation of curdlan (Ferreira et al., 2009), in berry-type fruits by spray drying (Robert \& Fredes, 2015), in purple corn, blueberry, and red raddish by cold-setting pectin-alginate gel (Barry, 2013), and in roselle and red cabbage by microwave-assisted technique (Zaidel et al., 2014). Recently, anthocyanins in glutinous black rice have been microencapsulated using maltodextrins by spray and freeze drying (Laokuldilok \& Kanha, 2016). However, nanoencapsulation of anthocyanins from black rice bran using chitosan-alginate nanoparticles has yet to be explored. Hence, this study was conducted.

\section{Materials and Methods}

\subsection{Rice Samples and Processing}

Ten Philippine traditional black rice varieties, namely, Galo, Galo Malagkit, Inatipan, Ittum, Kotinaw, Labitaris, Masbate, Ominio, Palanqui, and Pirurutong were used in this study. NSIC Rc160 was used as control sample due to its popularity among Filipino rice farmers. Two hundred grams of each variety was dehulled through a dehuller (THU-35A, Satake, Japan) to produce the brown rice and then further milled using a rice polisher (GrainMan Polisher No. 2, USA) to collect the bran. The recovered rice bran was sieved to obtain a finer and uniform particle size. The bran was stored in the refrigerator at $4^{\circ} \mathrm{C}$ prior to analysis.

\subsection{Screening of Rice Bran Samples}

Rice bran samples were screened for their total anthocyanin content (TAC). TAC was measured based on the optimized method of Abdel-Aal et al. (2006). About $300 \mathrm{mg}$ of rice bran samples was transferred into $25-\mathrm{mL}$ centrifuge tube (Falcon, USA) and added with $10 \mathrm{~mL}$ of acidified ethanol (85\% ethanol in $1 \mathrm{M} \mathrm{HCl}$ solution). The solutions were homogenized using vortex mixer (Vortex-Genie 2, Scientific Industries, Inc., USA), agitated for $1 \mathrm{~h}$ using a mechanical shaker (IKA ${ }^{\circledR}$ KS 260 Basic, USA) and centrifuged (Allegra x-22R, Beckman Coulter, USA) at $3000 \mathrm{rpm}$ for $15 \mathrm{~min}$. The supernatants were transferred into $50-\mathrm{mL}$ volumetric flask and diluted to mark with acidified ethanol. The absorbance of the solution was measured against the blank (acidified ethanol) at $535 \mathrm{~nm}$ using UV-Vis Spectrophotometer (DU 730, Beckman Coulter, USA).

The TAC of bran samples was calculated based on the cyanidin-3-glucoside content using the Lambert-Beer's Law as follows:

$\mathrm{TAC}(\mathrm{mg} / \mathrm{kg})=($ Absorbance $\mathrm{x}$ Volume of extract $\mathrm{x}$ MW x 10 $) /(1,000 \mathrm{x} \varepsilon \times \mathrm{x}$ mass $)$

$$
\text { Where: } \quad \varepsilon=\text { molar absorptivity of cyanidin-3-glucoside }(25,965 \mathrm{~L} / \mathrm{cm} \mathrm{mol})
$$

MW = molecular weight of cyanidin-3-glucoside $(449.2 \mathrm{~g} / \mathrm{mol})$

\subsection{Preparation of Anthocyanin Extracts}

Rice bran with the highest anthocyanin content was used as sample for the extraction and encapsulation of anthocyanins. Five hundred grams of rice bran was soaked with $1 \mathrm{~L}$ of $\mathrm{n}$-hexane in an Erlenmeyer flask to remove the oils and fats. The mixtures were magnetically stirred (IKA ${ }^{\circledR}$ C-MAG HS10, USA) for $5 \mathrm{~h}$, left to soak overnight, and vacuum filtered (Eyela, Tokyo Rikakikai Co., Ltd., Japan) using an ordinary filter paper. The bran residues were collected and oven-dried (DKN812, Yamato, Japan) at $60^{\circ} \mathrm{C}$ for $1 \mathrm{~h}$. After drying, the defatted 
bran was soaked with acidified ethanol, allowed to stand overnight, and then vacuum filtered through an ordinary filter paper. The filtrate was concentrated using a rotary vacuum evaporator (Eyela, Tokyo Rikakikai Co., Ltd., Japan), oven-dried at $50^{\circ} \mathrm{C}$, ground using mortar and pestle, and sieved (ASTM no. 40) to obtain a sample with uniform and finer particle size. The crude anthocyanin extract (CAE) powder was placed in a dark bottle, sealed, and stored in a refrigerator (NR-A7413ES, Panasonic, Philippines) at $4{ }^{\circ} \mathrm{C}$ prior to analysis and encapsulation.

\subsection{Preparation of Capsules}

Chitosan-alginate capsules were prepared through ionic pre-gelation and polyelectrolyte complex formation based on the modified method of De and Robinson (2003). Ionic pre-gelation was done by gradually adding 10 $\mathrm{mL}$ of $0.03 \mathrm{M} \mathrm{CaCl}_{2}$ solution using a $15-\mathrm{mL}$ syringe into $50 \mathrm{~mL}$ of $0.3 \%$ aqueous sodium alginate. The sodium alginate solution was sonicated (WUC-D22H, Wisd, Lab Instrument, Germany) during and after the addition of $\mathrm{CaCl}_{2}$ solution for $15 \mathrm{~min}$. The resulting pre-gel was constantly stirred (IKA ${ }^{\circledR}$ C-MAG HS10, USA) for another $10 \mathrm{~min}$ and about $20 \mathrm{~mL}$ of $0.08 \%$ chitosan solution was added to it. The suspensions were sonicated and stirred for $30 \mathrm{~min}$ and was equilibrated for $12 \mathrm{~h}$. The suspensions were then isolated by centrifugation (Allegra $\mathrm{x}-22 \mathrm{R}$, Beckman Coulter, USA) at $9,500 \mathrm{rpm}$ for $30 \mathrm{~min}$ at $4{ }^{\circ} \mathrm{C}$. The supernatant was collected for encapsulation efficiency analysis. The deposited mixture was re-dispersed in distilled water through vortex mixing (Vortex-Genie 2, Scientific Industries, Inc., USA). The samples were lyophilized using freeze-dryer (CoolSafe 110, Scanvac, Germany) and stored in the freezer (NR-A1009F, Panasonic, Philippines) at $-5^{\circ} \mathrm{C}$.

The amount of anthocyanins to be incorporated into the $\mathrm{CaCl}_{2}$ solution was varied (Table 1). The rest of the process was done the same for each treatment as the preparation of the blank chitosan-alginate.

Table 1. Treatments with their corresponding compositions

\begin{tabular}{cc}
\hline Treatment & Composition \\
\hline $\mathrm{T}_{0}$ & Chitosan-alginate \\
$\mathrm{T}_{1}$ & Chitosan-alginate $+10 \mathrm{mg} \mathrm{CAE}$ \\
$\mathrm{T}_{2}$ & Chitosan-alginate $+20 \mathrm{mg}$ CAE \\
$\mathrm{T}_{3}$ & Chitosan-alginate $+30 \mathrm{mg} \mathrm{CAE}$ \\
\hline
\end{tabular}

\subsection{Characterization of Anthocyanin-loaded Capsules}

Particle size and polydispersive index of anthocyanin-loaded capsules were measured using Zetasizer through dynamic light scattering (DLS). The samples were homogenized and diluted with distilled water to obtain a concentration of $0.01 \mathrm{~g} / \mathrm{L}$ prior to measurement.

Surface morphology of the anthocyanin-loaded capsules was determined using a Scanning Electron Microscope (SEM). Small amount of samples were transferred into a small holder and coated with Au-Pd using Ion Sputter (E1010, Hitachi, Japan). The samples were then transferred into the sample holder of the SEM apparatus (S3400N, Hitachi, Japan) set at $15 \mathrm{kV}$.

Chemical properties of the anthocyanin-loaded capsules were characterized using a Fourier Transform Infrared (FTIR) spectrophotometer (Horizon MB3000, Canada). The spectra of the samples were recorded between $4000-400 \mathrm{~cm}^{-1}$.

\subsection{Encapsulation Efficiency of the Anthocyanin-loaded Capsules}

TAC of the anthocyanin-loaded capsules was determined using the modified method of Santos et al. (2013). The TAC of unencapsulated samples was measured at $535 \mathrm{~nm}$ using UV-Vis Spectrophotometer (U-3210, Hitachi, Japan). The absorbance of the original anthocyanin extract was used in the Lambert-Beer's formula to calculate the concentration of the unencapsulated anthocyanin. Encapsulation efficiency (\%EE) was computed as follows:

$$
\% \mathrm{EE}=\left[\left(\text { Concentration }_{(\text {original) }}-\text { Concentration }_{(\text {unencapsulated })}\right) / \text { Concentration }_{(\text {original) }}\right] \times 100
$$

\subsection{Antioxidant Scavenging Activity}

Antioxidant scavenging activity (ASA) of anthocyanin-loaded capsules was determined through 2,2-diphenyl-1-picrylhydrazyl (DPPH) radical scavenging assay. About $100 \mathrm{mg}$ of sample was weighed and transferred into a centrifuge tube. The tube was added with $3 \mathrm{~mL}$ of absolute methanol and agitated overnight. The tubes were then mixed using a vortex mixer (Vortex-Genie 2, Scientific Industries, Inc., USA) and were centrifuged (Allegra x-22R, Beckman Coulter, USA) at $3000 \mathrm{rpm}$ for $15 \mathrm{~min}$ at $25^{\circ} \mathrm{C}$. About $0.5 \mathrm{~mL}$ of aliquot was transferred into a test tube containing $5 \mathrm{~mL}$ of freshly prepared $0.10 \mathrm{mM} \mathrm{DPPH}$. The samples were stood for 
$1 \mathrm{~h}$ and the absorbance was measured against the blank (methanol) at $517 \mathrm{~nm}$ using UV-Vis Spectrophotometer (U-3210, Hitachi, Japan). The ASA was calculated as follows:

$$
\% \mathrm{ASA}=\left[\left(\text { Absorbance }_{(\text {blank) }}-\text { Absorbance }_{(\text {sample) }} / \text { Absorbance }_{(\text {blank })}\right] \times 100\right.
$$

\subsection{Statistical Analysis}

Data were reported as the mean of three measurements \pm SD. One-way Analysis of Variance (ANOVA) was used to determine the significant differences among means. Tukey's test was employed to compare treatment means for the screening of bran samples, and determination of particle sizes and encapsulation efficiency of the anthocyanin-loaded capsules. Least Significant Difference (LSD) test was used to compare the treatment means for the DPPH radical scavenging activity at $\mathrm{p}<0.05$.

\section{Results and Discussion}

\subsection{Anthocyanin Content of Rice Bran Samples}

Among the bran samples, Ominio bran had the highest anthocyanin content $(36.11 \mathrm{mg} / \mathrm{g})$ while the control variety NSIC Rc160 had the lowest $(0.55 \mathrm{mg} / \mathrm{g})$. The result confirms our previous findings on the screening of rice bran with maximum health promoting properties wherein Ominio bran had the highest anthocyanin content among the black rice varieties (Bulatao et al., 2016). Anthocyanin is the major antioxidants in rice and was reported to exhibit potent antioxidant activity that could neutralize free radicals in the body. Imbalance between the production of antioxidants and free radicals in the body may lead to oxidative stress, which are implicated in many chronic illnesses. Since Ominio had the highest anthocyanin content, it has the potential to be used as functional ingredient for the development of nutraceutical food and pharmaceutical products. Thus, Ominio bran was selected as sample for the preparation of crude anthocyanin extract (CAE) for encapsulation.

Table 2. Anthocyanin content of black rice bran samples

\begin{tabular}{lc}
\hline Rice Bran Sample & Anthocyanin Content $(\mathrm{mg} / \mathrm{g})$ \\
\hline NSIC Rc160 & $0.6 \pm 0.0^{\mathrm{h}}$ \\
Galo 1 & $4.4 \pm 0.0^{\mathrm{f}}$ \\
Galo Malagkit & $10.7 \pm 0.3^{\mathrm{c}}$ \\
Inatipan & $5.3 \pm 0.2^{\mathrm{e}}$ \\
Ittum & $7.1 \pm 0.5^{\mathrm{d}}$ \\
Kotinaw & $7.1 \pm 0.2^{\mathrm{d}}$ \\
Labitaris & $3.5 \pm 0.2^{\mathrm{g}}$ \\
Masbate & $5.3 \pm 0.2^{\mathrm{e}}$ \\
Ominio & $36.1 \pm 0.7^{\mathrm{a}}$ \\
Palanqui & $3.7 \pm 0.1^{\mathrm{fg}}$ \\
Pirurutong & $19.6 \pm 0.3^{\mathrm{b}}$ \\
\hline
\end{tabular}

*Similar letter superscript of means signifies no significant difference at $\mathrm{p}<0.05$ using Tukey's test.

\subsection{Encapsulation of Anthocyanin}

Powdered CAE from Ominio bran was encapsulated using chitosan-alginate polyelectrolyte complex matrix. The freeze-dried capsules were observed to be white for the blank while purplish to blackish for the anthocyanin-loaded capsules. Similar characteristics of the product were obtained with those of the encapsulated anthocyanin extract from Jabuticaba skins using polyethylene glycol (Santos et al., 2013).

\subsection{Characterization of Anthocyanin-Loaded Chitosan-Alginate Capsules}

\subsubsection{Fourier Transform Infrared Spectroscopy}

The FTIR spectra of alginate and chitosan showed stretching vibrations of $\mathrm{O}-\mathrm{H}$ and $\mathrm{N}-\mathrm{H}$ bonds in the range of $3600-3000 \mathrm{~cm}^{-1}$ (Figure 1). The asymmetric and symmetric stretching of carboxyl anions were observed at 1604 $\mathrm{cm}^{-1}$ and $1412 \mathrm{~cm}^{-1}$, respectively, while absorption band of the bending of the secondary amide of chitosan was observed at $1653 \mathrm{~cm}^{-1}$. For chitosan, stretching vibrations of $\mathrm{C}-\mathrm{O}$ at 1066, 1026, and $895 \mathrm{~cm}^{-1}$ indicated the presence of secondary $(-\mathrm{CH}-\mathrm{OH})$ and primary $\left(-\mathrm{CH}_{2}-\mathrm{OH}\right)$ hydroxyl groups, and cyclic ether bond (C-O-C), respectively (Chen et al., 2004).

For the chitosan-alginate nanoparticle spectra $\left(\mathrm{T}_{0}\right)$, the $\mathrm{O}-\mathrm{H}$ and $\mathrm{N}-\mathrm{H}$ bond absorption peaks ranged from $3600-3000 \mathrm{~cm}^{-1}$. Moreover, the stretching of the $\mathrm{N}-\mathrm{H}$ bond with the $\mathrm{C}=\mathrm{O}$ group (amide) was observed at the 
peaks $1607 \mathrm{~cm}^{-1}$ and $1561 \mathrm{~cm}^{-1}$, which implies that there is an interaction between the carboxyl and amino group between the polymers. Some distinct peaks of chitosan disappeared in the chitosan-alginate spectra due to its low concentration in the polyelectrolyte mixture. Sankalia et al. (2007) reported that the disappearance of some peaks might be due to the presence of multi-interactions of polymers like electrostatic and hydrogen bonding.

The incorporation of anthocyanin into the chitosan-alginate capsules was also investigated using FTIR (Figure 2). Anthocyanin extract displayed peak vibrations at $3330 \mathrm{~cm}^{-1}$ (O-H stretch), $2934 \mathrm{~cm}^{-1}$ (=C-H stretch), and 1021 $\mathrm{cm}^{-1}$ (C-O stretch). Vibration band at $1636 \mathrm{~cm}^{-1}(\mathrm{C}=\mathrm{O}$ stretch from fructose) was observed from the spectra of anthocyanin (Akmed et al., 2013). Smaller peak intensities were noticed on the spectral data of the anthocyanin-loaded chitosan-alginate capsules due to the lower concentration of the treatments as compared with the CAE.

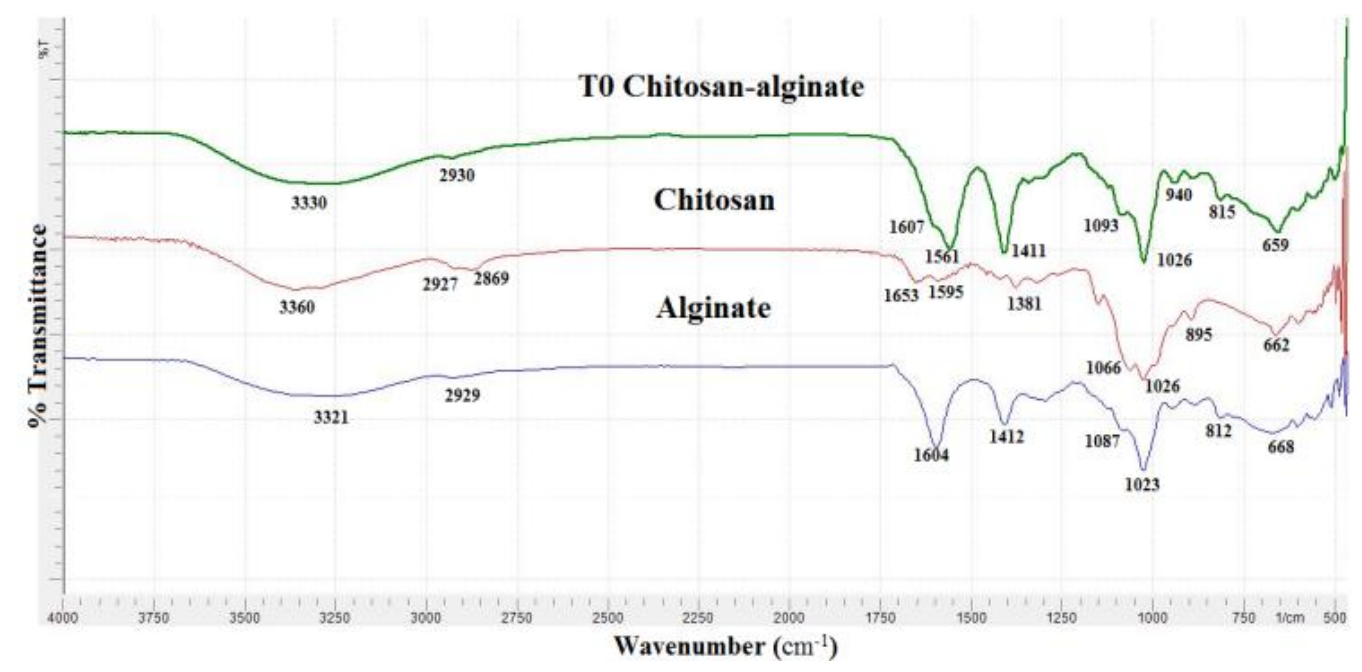

Figure 1. FTIR spectra of chitosan-alginate capsules $\left(\mathrm{T}_{0}\right)$, chitosan and sodium alginate

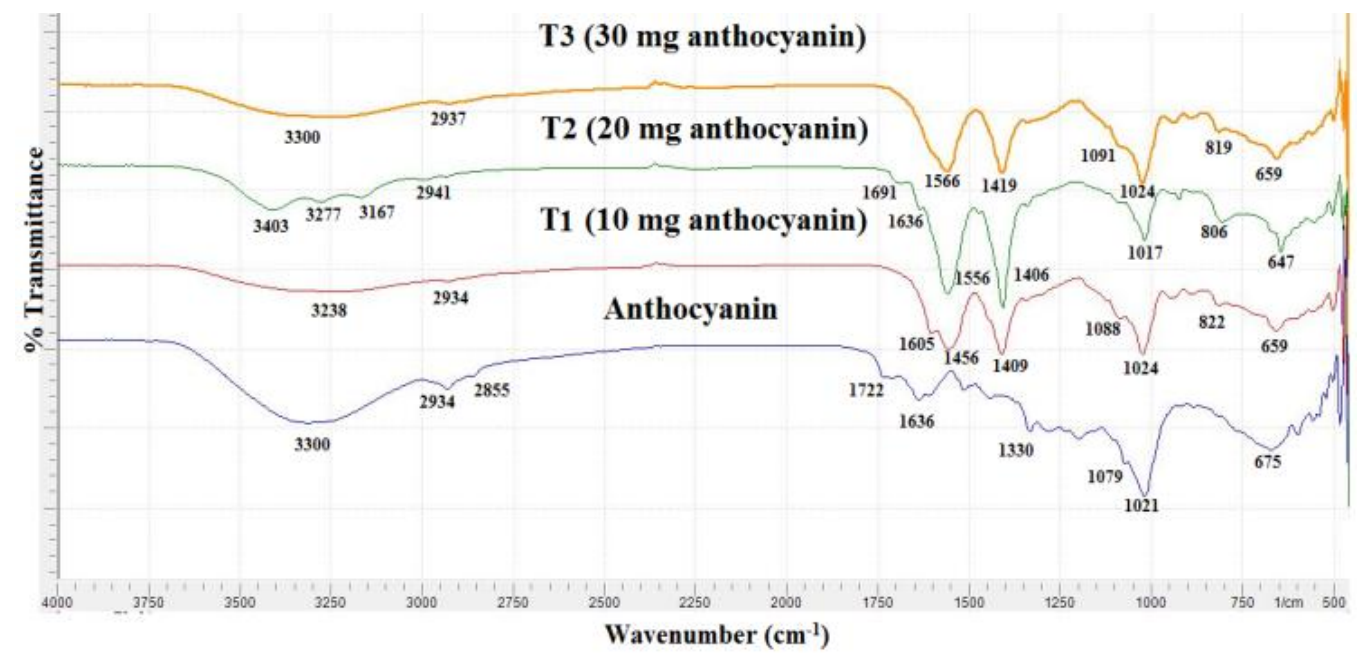

Figure 2. FTIR spectra of anthocyanin extracts and the anthocyanin-loaded capsules

\subsubsection{Scanning Electron Microscopy}

The surface morphology of each treatment was evaluated using a Scanning Electron Microscope (Figure 3). The surface of $\mathrm{T}_{0}$ showed irregular spherical, rough particles; $\mathrm{T}_{1}$ was rough with elongated shape; while $\mathrm{T}_{2}$ was rough with bigger irregular round shapes. On the contrary, distinct protruding particles with smooth spherical solid characteristics were on the surface of $T_{3}$. The clumping observed in each treatment may be attributed to the absence of a cryoprotectant during the freeze-drying of samples. Abdelwahed et al. (2006) reported that the use of cryoprotectant such as sucrose and polyvinyl pyrrolidone could preserve the integrity of the capsules. 

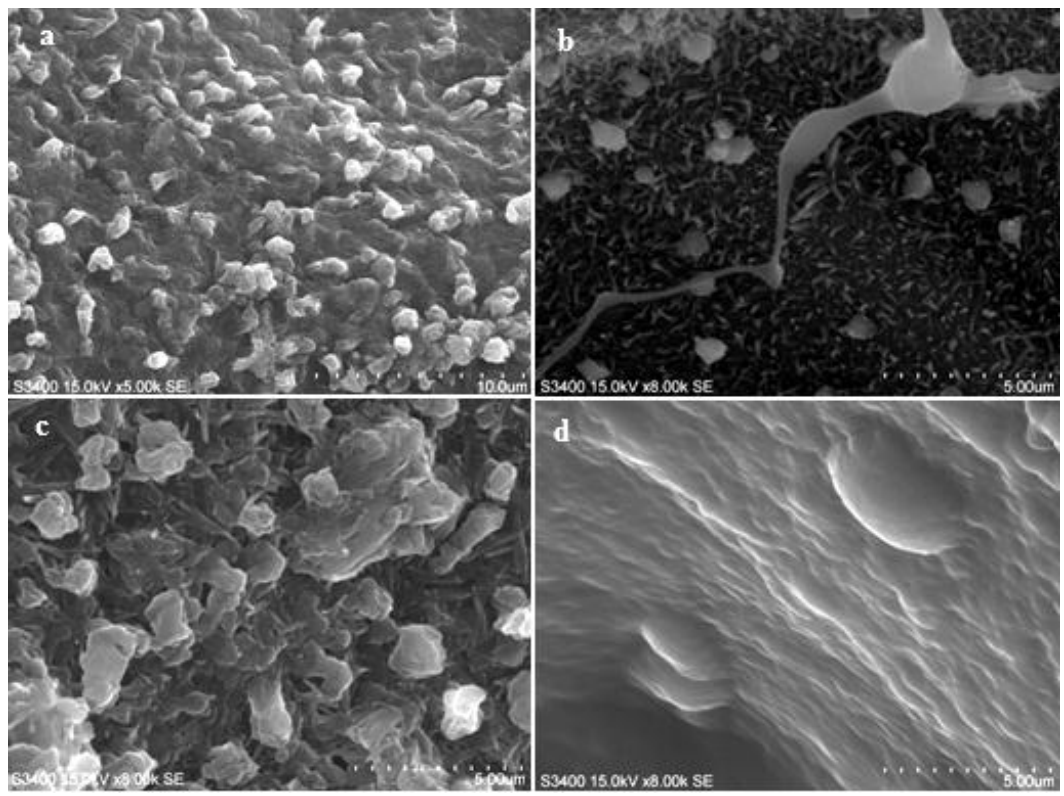

Figure 3. SEM images of the different loading concentrations of anthocyanin: a) $\mathrm{T}_{0}$-blank b) $\left.\mathrm{T}_{1}-10 \mathrm{mg} \mathrm{c}\right) \mathrm{T}_{2}-20$ mg d) $\mathrm{T}_{3}-30 \mathrm{mg}$. Scale bar: $10 \mu \mathrm{m}(\mathrm{a}) ; 5 \mu \mathrm{m}(\mathrm{b}, \mathrm{c}, \mathrm{d})$

\subsubsection{Particle Size and Polydispersive Index through Dynamic Light Scattering}

The particle size and polydispersive index of the anthocyanin-loaded capsules was measured using Zetasizer (Table 3). As expected, $\mathrm{T}_{0}$ had the smallest particle size $(358.5 \mathrm{~nm})$ because it does not contain the bioactive compound. Among the anthocyanin-loaded treatments, $T_{3}$ had the smallest particle size $(467.9 \mathrm{~nm})$ while $T_{2}$ had the largest $(635.9 \mathrm{~nm})$. Despite the increasing anthocyanin concentrations, the particle size of the anthocyanin-loaded capsules decreases. This is because higher concentration of anthocyanins allows the nanoparticles to fully disperse in a larger surface area, thus decreasing its particle size due to the intercalated nanoparticles. This reaction follows exfoliation process in a mono disperse layer covering the surface area of the anthocyanin. Nevertheless, all anthocyanin-loaded capsules were categorized as nanocapsule (1-1000 nm) since the particle size of the treatments were lower than $1000 \mathrm{~nm}$ (Dineskumar et al., 2013).

For the polydispersive index (PDI), $\mathrm{T}_{3}$ had the lowest PDI among the treatments (0.31). PDI describes the width of the particle size distribution and usually ranges from 0 to 1 , of which the higher value signifies less homogenous particle size distribution (Rodriguez et al., 2004). Thus, $\mathrm{T}_{3}$ showed significantly homogenous particle size distribution as compared with the other treatments. This might be due to the higher concentration of anthocyanins, which strengthens the interactions within the polymers.

Table 3. Average particle size and polydispersive index anthocyanin-loaded capsules

\begin{tabular}{ccc}
\hline Treatment & Average Particle Size $(\mathrm{nm})$ & Polydispersive Index \\
\hline $\mathrm{T}_{0}$ & $358.5 \pm 73.2^{\mathrm{a}}$ & $0.57 \pm 0.02^{\mathrm{b}}$ \\
$\mathrm{T}_{1}$ & $572.3 \pm 125.8^{\mathrm{b}}$ & $0.69 \pm 0.09^{\mathrm{bc}}$ \\
$\mathrm{T}_{2}$ & $635.9 \pm 88.4^{\mathrm{b}}$ & $0.76 \pm 0.07^{\mathrm{c}}$ \\
$\mathrm{T}_{3}$ & $467.8 \pm 17.0^{\mathrm{ab}}$ & $0.31 \pm 0.08^{\mathrm{a}}$
\end{tabular}

*Similar letter superscript of means signifies no significant difference at $\mathrm{p}<0.05$ using Tukey’s test.

\subsection{Encapsulation Efficiency of the Capsules}

Encapsulation efficiency showed significant variations among the treatment tested. Among the treatments, $\mathrm{T}_{3}$ had the highest encapsulation efficiency of $68.9 \%$. The obtained encapsulation efficiency in this study is slightly lower, which may be explained through the leaching of the water-soluble anthocyanin during encapsulation. Abreu et al. (2010) stated that the encapsulation efficiency using a water-in-oil emulsion is better than the aqueous media. In general, the higher amount of anthocyanins to be encapsulated, the higher its encapsulation efficiency. 
Table 4. Encapsulation efficiency of the prepared capsules

\begin{tabular}{ccc}
\hline Treatments & Encapsulation Efficiency (\%) & Antioxidant Scavenging Activity (\%) \\
\hline $\mathrm{T}_{1}$ & $56.87 \pm 0.08^{\mathrm{b}}$ & $8.4 \pm 0^{\mathrm{b}}$ \\
$\mathrm{T}_{2}$ & $56.34 \pm 0.60^{\mathrm{b}}$ & $7.1 \pm 0^{\mathrm{b}}$ \\
$\mathrm{T}_{3}$ & $68.92 \pm 1.29^{\mathrm{a}}$ & $38.3 \pm 0^{\mathrm{a}}$ \\
\hline
\end{tabular}

*Similar letter superscript of means signifies no significant difference at $\mathrm{p}<0.05$ using Tukey’s test.

\subsection{Antioxidant Scavenging Activity of Anthocyanin-Loaded Capsules}

Among the different loading concentrations of anthocyanin, $\mathrm{T}_{3}$ had the highest antioxidant scavenging activity (ASA) of $38.3 \%$ while $\mathrm{T}_{1}$ and $\mathrm{T}_{2}$ had the lowest with ASA of $8.4 \%$ and $7.1 \%$, respectively. Similar trend was observed with the ASA and encapsulation efficiency of the capsules. The obtained ASA of $\mathrm{T}_{3}$ was quite high given that the concentration of that treatment is only $30 \mathrm{mg}$. This might be explained by the type of the solvent used in the extraction of anthocyanin from the capsules. According to Barry (2013), the ideal concentration of methanol as extractant for the anthocyanin-loaded alginate-pectin gels was $85 \%$. They also suggested that using $70 \%$ acetone could enhance the efficiency of the analysis by almost $100 \%$.

\section{Conclusion}

Ominio bran contained the highest amount of anthocyanin among the black rice samples that were screened. Anthocyanin extracts were successfully encapsulated using chitosan-alginate nanoparticles. Anthocyanin-loaded capsules from black rice bran produced a purple to black powder. Chemical properties showed that anthocyanins were well-incorporated in the chitosan-alginate framework. SEM analysis suggested the presence of clumping on the surface due to freeze-drying. Moreover, analysis of capsules using zetasizer confirmed that all anthocyanin-loaded capsules were nanocapsules since their particle size was less than $1000 \mathrm{~nm}$. Among the treatments, $T_{3}$ had the highest encapsulation efficiency and antioxidant activity. Finally, the study concluded that anthocyanin can be encapsulated using chitosan-alginate nanoparticles. The encapsulated anthocyanin extract can be used as functional material for the development of high-value food and pharmaceutical products.

\section{References}

Abdelwahed, W., Degobert, G., \& Fessi, H. (2006). Freeze-drying of nanocapsules: Impact of annealing on the drying process. International Journal of Pharmaceutics, 324(1), 74-82. https://doi.org/10.1016/j.ijpharm.2006.06.047

Abreu, F. O. M. S. (2010). Effect of the preparation method on the drug loading of alginate-chitosan microspheres. eXPRESS Polymer Letters, 4(8), 456-464. https://doi.org/10.3144/expresspolymlett.2010.58

Ahmed, J. K., Salih, H. A. M., \& Hadi, G. (2013). Anthocyanins in red beet juice act as scavengers for heavy metals ions such as lead and cadmium. Journal of Science and International Technology, 2(3), 269-274.

Andersen, O. M., \& Jordheim, M. (2006). The anthocyanins. In O.M. Andersen \& K.R. Markham (Eds.), Flavonoids chemistry, biochemistry and Applications (pp. 471-552). USA: CRC Press Taylor \& Francis Group.

Barry, A. (2013, March). Encapsulation, color stability, and distribution of anthocyanins from purple corn (zea mays 1.), blueberry (vaccinium sp.), and red radish (raphanus sativus) in a cold-setting pectin-alginate gel. Paper presented at the 27th Hayes Graduate Research Forum, Columbus, OH. Abstract retrieved from http://hdl.handle.net/1811/54808

Bulatao, R. M., Asuncion, J. M. M., Lambanicio, J. C., Delos Santos, C. L. D., Tejada, J. M. D., Labastilla, E. M., \& Corpuz, H. M. (2016). Screening of Philippine Traditional Pigmented Rice Bran with Maximum Nutrients and Health-Promoting Properties. The Philippine Agricultural Scientist, 99(2), 135-141.

Cavalcanti, R. N., Santos, D. T., \& Meireles, M. A. A. (2011). Non-thermal stabilization mechanisms of anthocyanins in model and food systems-An overview. Food Research International, 44(2), 499-509. https://doi.org/10.1016/j.foodres.2010.12.007

Chen, S. C., Wu, Y. C., Mi, F. L., Lin, Y. H., Yu, L. C., \& Sung, H. W. (2004). A novel pH-sensitive hydrogel composed of N,O-carboxymethyl chitosan and alginate cross-linked by genipin for protein drug delivery. Journal of Controlled Release, 96(2), 285-300. https://doi.org/10.1016/j.jconrel.2004.02.002

De, S., \& Robinson, D. (2003). Polymer relationships during preparation of chitosan-alginate and 
poly-1-lysine-alginate nanospheres. Journal of Controlled Release, 89(1), 101-112. https://doi.org/10.1016/S0168-3659(03)00098-1

Dineshkumar, B., Krishnakumar, K., John, A., Paul, D., Cherian, J., \& Panayappan, L. (2013). Nanocapsules : A Novel Nano-Drug Delivery System. International Journal of Research in Drug Delivery, 3(1), 1-3.

Galindo-Rodriguez, S., Allémann, E., Fessi, H., \& Doelker, E. (2004). Physicochemical parameters associated with nanoparticle formation in the salting-out, emulsification-diffusion, and nanoprecipitation methods. Pharmaceutical Research, 21(8), 1428-1439. https://doi.org/10.1023/B:PHAM.0000036917.75634.be

George, M., \& Abraham, T. E. (2006). Polyionic hydrocolloids for the intestinal delivery of protein drugs: Alginate and chitosan - a review. Journal of Controlled Release, 114(1), 1-14. https://doi.org/10.1016/j.jconrel.2006.04.017

Gupta, V. K., \& Karar, P. K. (2011). Optimization of Process Variables for the Preparation of Chitosan - Alginate Nanoparticles. International Journal of Pharmacy and Pharmaceutical Sciences, 3, 3-5.

Moongngarm, A., Daomukda, N., \& Khumpika, S. (2012). Chemical Compositions, Phytochemicals, and Antioxidant Capacity of Rice Bran, Rice Bran Layer, and Rice Germ. APCBEE Procedia, 2, 73-79. https://doi.org/10.1016/j.apcbee.2012.06.014

Nagavarma, B. V. N., Yadav, H. K. S., Ayaz, A., Vasudha, L. S., \& Shivakumar, H. G. (2012). Different techniques for preparation of polymeric nanoparticles- A review. Asian Journal of Pharmaceutical and Clinical Research, 5, 16-23

Nedovic, V., Kalusevic, A., Manojlovic, V., Levic, S., \& Bugarski, B. (2011). An overview of encapsulation technologies for food applications. Procedia Food Science, 1, 1806-1815. https://doi.org/10.1016/j.profoo.2011.09.265

Philippine Statistics Authority (2016). Palay and corn: volume of production by ecosystem/crop type, by quarter, by semester, by region and by province. Retrieved from http://countrystat.psa.gov.ph/selection.asp

Rinaudo, M. (2006). Chitin and chitosan: Properties and applications. Progress in Polymer Science, 31(7), 603-632. https://doi.org/10.1016/j.progpolymsci.2006.06.001

Rowe, R. C., Sheskey, P. J., \& Quinn, M. E. (Eds.). (2009). Handbook of Pharmaceutical Excipients. USA: Pharmaceutical Press And American Pharmacists Association.

Sankalia, M. G., Mashru, R. C., Sankalia, J. M., \& Sutariya, V. B. (2007). Reversed chitosan-alginate polyelectrolyte complex for stability improvement of alpha-amylase: Optimization and physicochemical characterization. European Journal of Pharmaceutics and Biopharmaceutics, 65(2), 215-232. https://doi.org/10.1016/j.ejpb.2006.07.014

Santos, D. T., Albarelli, J. Q., Beppu, M. M., \& Meireles, M. A. A. (2013). Stabilization of anthocyanin extract from jabuticaba skins by encapsulation using supercritical $\mathrm{CO} 2$ as solvent. Food Research International, 50(2), 617-624. https://doi.org/10.1016/j.foodres.2011.04.019

Sharp, R. (2013). A review of the applications of chitin and its derivatives in agriculture to modify plant-microbial interactions and improve crop yields. Agronomy, 3(4), 757-793. https://doi.org/10.3390/agronomy3040757

Shipp, J., \& Abdel-Aal, E.-S. M. (2010). Food applications and physiological effects of anthocyanins as functional food ingredients. The Open Food Science Journal, 4(1), 7-22. https://doi.org/10.2174/1874256401004010007

Skaugrud, Ø., Hagen, A., Borgersen, B., \& Dornish, M. (1999). Biomedical and pharmaceutical applications of alginate and chitosan. Biotechnology and Genetic Engineering Reviews, 16(1), 23-40. https://doi.org/10.1080/02648725.1999.10647970

Wandrey, C., Bartkowiak, A., \& Harding, S.E. (2010). Materials for encapsulation. In J. Zuidam \& V.A. Nedovic (Eds.), Encapsulation technologies for active food ingredients and food processing, 3, 31-100. New York, USA: Springer New York. https://doi.org/10.1007/978-1-4419-1008-0

\section{Copyrights}

Copyright for this article is retained by the author(s), with first publication rights granted to the journal.

This is an open-access article distributed under the terms and conditions of the Creative Commons Attribution license (http://creativecommons.org/licenses/by/4.0/). 